\title{
Premature Loss of Primary Molars in Children from Highly Endemic Fluoride District of Telangana, India: A Cross- sectional Study
}

\author{
Saraswati Srikanth Raju ${ }^{1}$, Sadhana Majhi ${ }^{2}$, Kiranmayi Merum ${ }^{3}$, Srujana Mudusu Palicarp ${ }^{4}$, Eddula Rajendra Reddy ${ }^{5}$, \\ Mahali Sai Divya ${ }^{6}$
}

\begin{abstract}
Aims and objectives: Premature loss of primary molars in children predisposes to future orthodontic treatment needs, which may affect the child both nutritionally and psychologically. The main aim of this study was to evaluate the prevalence of premature loss of primary molars in 5-9-year-old school children of Highly Endemic Fluoride District from Telangana state, India.

Materials and methods: A single calibrated examiner performed all clinical examinations under natural light using a mouth mirror and probe. A total of 1,124 children ( 562 boys and 562 girls) aged between 5 years and 10 years were included in the study. Data including age, carious teeth, and missing teeth were collected. These data were then statistically analyzed.

Results: The results showed that $7.82 \%$ of sample children had an early loss of primary teeth with boys showing an increased incidence of loss of primary teeth $(5.33 \%)$ and the children in the age group of 7-8 years had greater prevalence. The most common missing tooth was the primary first molar (58.4\%) followed by the primary second molar $(41.5 \%)$.

Conclusion: In endemic fluoride areas, the prevalence of early loss of primary teeth was less when compared with other studies done in nonfluoride areas.

Clinical significance: Educational and preventive programs about oral health should be implemented in schools which would further reduce premature loss of primary teeth and eventually reduce malocclusion problems in children.

Keywords: Caries, Children, Fluoride, Premature loss, Primary molar.

World Journal of Dentistry (2021): 10.5005/jp-journals-10015-1859
\end{abstract}

\section{INTRODUCTION}

Maintenance of primary teeth till their exfoliation is essential for the proper establishment of normal permanent occlusion. ${ }^{1,2}$ The premature or early loss is defined as the loss of a deciduous tooth before the time of its natural exfoliation ${ }^{3}$ and it can be caused by many factors such as inappropriate oral hygiene, dental injuries, and tooth decay. ${ }^{4}$ The premature loss of primary teeth may reduce the arch length required for the succeeding tooth hence predisposes malocclusion in the sagittal, transverse, and vertical planes. ${ }^{5,6}$ Early loss of primary first molars can cause distal drifting of the primary canine if the loss occurs during the active eruption of the permanent lateral incisors. Primary second molars serve as a guide for erupting permanent first molars, so their early loss especially in the maxillary arch will result in arch length reduction due to mesial migration of permanent molars. ${ }^{5,7}$

The negative relationship between the fluoride concentration of drinking water and dental caries has been established in the literature. The main etiopathogenic action of fluorides in reducing dental caries and thereby preventing early loss of primary teeth is through the ionic exchange between the enamel surface of the tooth and the fluoride. This reaction will change the surface calcium hydroxyapatite of enamel to calcium fluorapatite, which is more resistant to dissolution in acids. ${ }^{8}$

General dentists prefer to extract a grossly decayed primary tooth or a primary tooth without coronal structure rather than restore it multiple times. ${ }^{9}$ Lack of parental knowledge about restoring such primary teeth and also lack of knowledge about
${ }^{1,3-6}$ Department of Pedodontics, Kamineni Institute of Dental Sciences, Narketpally, Nalgonda, Telangana, India

${ }^{2}$ Department of Dentistry, Kamineni Institute of Dental Sciences, Narketpally, Nalgonda, Telangana, India

Corresponding Author: Mahali Sai Divya, Department of Pedodontics, Kamineni Institute of Dental Sciences, Narketpally, Nalgonda, Telangana, India, Phone: +916301417743, e-mail: divya.mahali@ gmail.com

How to cite this article: Raju SS, Majhi S, Merum K, et al. Premature Loss of Primary Molars in Children from Highly Endemic Fluoride District of Telangana, India: A Cross-sectional Study. World J Dent 2021;12(5):372-375.

Source of support: Nil

Conflict of interest: None

consequences of early loss of deciduous teeth can be some of the contributing factors. ${ }^{10}$ Hence, this study was undertaken to know the prevalence of early loss of primary teeth among children in the Nalgonda district (Highly Endemic Fluoride Area) owing to the severity of consequences.

\section{Materials and Methods}

This cross-sectional study was approved by the Ethical Review Committee and Institutional Review Board, Kamineni Institute of Dental Sciences, Narketpally, Telangana, India. This study was 
conducted during a time period of October to December 2019. After concerning the district fluoride medical officer of Nalgonda district, a list of 10 highly endemic fluoride mandal areas where the concentration of fluoride in drinking water is above $4.1 \mathrm{ppm}$ was obtained. Five mandals of these highly endemic fluoride areas were selected by simple random sampling strategy, i.e., (1) Yellareddygudem (Narketpally mandal), (2) Gundlepally (Nalgonda mandal), (3) Jangareddy gudem (Thipparthy mandal), (4) Kothularam (Munugodu mandal), and (5) Bangarigadda (chandur mandal). Schools from these selected areas were again selected by the lottery method of simple random sampling technique. A letter of permission to examine the school children was given to the head of the schools and permission was obtained. Written informed consent was obtained from the parents or guardians. The children between the age group of 5 years and 10 years and whose parent or guardian agreeing to participate in the study were included. The medically comprised children, parent or guardian not willing to participate, and children with uncooperative behavior were excluded from the study.

The early loss was classified according to the chronological age table of an eruption of the permanent teeth proposed by Kronfeld ${ }^{11}$ and decreasing 12 months as proposed by Cardoso et al. ${ }^{2}$ The study population included 1,124 (562 boys and 562 girls) school children between the age group of 5 years and 10 years in Nalgonda district. Children were made to sit in an upright position using a wall as the headrest and dental examination was carried out. Intraoral examination was performed by a single calibrated examiner under adequate natural light using a mouth mirror and probe and the survey form was filled by a trained dentist. All the relevant data including age, sex, and general health were recorded through individual interviews conducted by a researcher on the day of the dental check-up. Data on carious teeth and missing teeth were collected using DMFT/def index using WHO criteria 1997. Intraoral photographs of missing teeth were taken. After completion of screening in each school, oral hygiene instructions were given, and brushing technique was demonstrated to the children. The acquired data were tabulated and then subjected to statistical analysis.

\section{Results}

In this present study, 1,124 school children were included and premature loss of primary molars was found in 88 children with 154 primary teeth missing (7.82\%) and boys (5.33\%) had a higher prevalence of premature loss when compared with the girls (2.4\%) (Table 1). The most commonly lost tooth was the primary first molar (58.4\%) followed by the primary second molar (41.5\%). Of the four primary molars, 84 (mandibular right first molar) with $18.1 \%$ found to be most frequently prematurely lost tooth followed by 64 (maxillary left first primary molar) with $16.8 \%$ (Table 2 ). Children with an early loss in the only mandibular arch (48\%) are more prevalent followed by early loss only in a maxillary arch (35.7\%) and both the arches (16.2\%) (Table 3). Precocious loss of primary teeth was higher in the right side of the dental arch (51\%) when compared with the left side of the arch (49\%). The prevalence of premature loss of primary teeth was higher in the 7-8-year age group followed by 8-9-year age group children (Table 4).

When the prevalence of caries in the study population was assessed, it was found in the 326 children (29\%) of the sample, with boys (17.97\%) had a higher prevalence of caries compared with girls (11.03\%). The most frequent caries-affected tooth in the study population was 85 (lower right second molar) followed by 75
Table 1: Distribution of schoolchildren with the early loss of primary teeth according to gender

\begin{tabular}{lllrl}
\hline & $\begin{array}{l}\text { Children } \\
\text { with tooth } \\
\text { loss (\%) }\end{array}$ & $\begin{array}{l}\text { Children } \\
\text { without } \\
\text { tooth loss } \\
\text { (\%) }\end{array}$ & Total & $\begin{array}{l}\text { Prevalence } \\
\text { (\%) }\end{array}$ \\
\hline Mender & $60(5.33)$ & $502(44.6)$ & 562 & 10.6 \\
Female & $28(2.49)$ & $532(47.3)$ & 562 & 4.9 \\
Total & $88(7.82)$ & $1,034(91.9)$ & 1,124 & \\
\hline
\end{tabular}

Table 2: Distribution of premature loss primary teeth according to gender

\begin{tabular}{lccc}
\hline Tooth & Boys & Girls & Prevalence \\
\hline 54 & 8 & 6 & $14(9)$ \\
55 & 12 & 2 & $14(9)$ \\
64 & 22 & 4 & $26(16.8)$ \\
65 & 12 & 4 & $16(10.3)$ \\
74 & 10 & 12 & $22(14.2)$ \\
75 & 10 & 2 & $12(7.7)$ \\
84 & 20 & 8 & $28(18.1)$ \\
85 & 14 & 8 & $22(14.2)$ \\
Total & 108 & 46 & $154(100)$ \\
\hline
\end{tabular}

Table 3: Prevalence of early loss of primary teeth according to the arches

\begin{tabular}{lcc}
\hline & \multicolumn{3}{c}{ Children with teeth } \\
loss & Percentage \\
\hline Maxilla & 55 & 35.8 \\
Mandible & 74 & 48 \\
Both & 25 & 16.2 \\
Total & 154 & 100 \\
\hline
\end{tabular}

(lower left second molar). The prevalence of caries was higher in the 7-8-year age group followed by the 8-9-year age group of children.

\section{Discussion}

Pedodontists have traditionally accepted active supervision of the developing dentition as a major responsibility. Management of space problems associated with the transitional stages from primary to permanent dentition is a routine component of pedodontic practice. $^{12}$

The prevalence of the early loss of primary teeth in the present study might be because many practitioners elect to extract primary teeth than trying to salvage them. ${ }^{9}$ It might also be because parents do not care about primary teeth as they have an idea that primary teeth will be replaced with permanent teeth. ${ }^{2}$ In the present study, the prevalence of early loss of primary teeth was found in 88 children with a percentage of $7.82 \%$ which is comparatively lower to other studies conducted in non-fluoride areas, which can be attributed to anti-cariogenic action of fluoride in the Nalgonda district, an endemic fluorosis area. ${ }^{13-15}$

In our study, boys had a higher prevalence of premature loss of primary teeth compared with girls and these results are similar to studies conducted earlier. ${ }^{13-15}$ Mahejabeen et al. in their study have quoted that the increased dmft scores in boys could be attributed to diet, geographic location, and cultural differences seen in the Indian 
Early Loss of Primary Molars

Table 4: Distribution of children with premature loss of primary teeth according to age and gender

\begin{tabular}{|c|c|c|c|c|c|c|}
\hline \multirow[b]{2}{*}{ Gender } & \multicolumn{5}{|c|}{ Age, $P P P$} & \multirow[b]{2}{*}{$n(\%)$} \\
\hline & $5-6$ & $6-7$ & $7-8$ & $8-9$ & $9-10$ & \\
\hline Boys & 4 & 4 & 24 & 16 & 12 & $60(68.1)$ \\
\hline Girls & 00 & 4 & 6 & 8 & 10 & $28(31.8)$ \\
\hline Total & $4(4.5 \%)$ & $8(9 \%)$ & $30(34 \%)$ & $24(27.2 \%)$ & $22(25 \%)$ & $88(100)$ \\
\hline
\end{tabular}

society, where boys are given priority. ${ }^{16}$ However, contrast results were seen in studies conducted by Murshid et al. ${ }^{4}$ and Lopez-Gomez et al. ${ }^{17}$ in which both genders were equally susceptible to caries.

The tooth most commonly affected by early loss in the present study was 84 followed by 64 and these results were similar to the study conducted by Ahamed et al., ${ }^{13}$ Reddy et al., ${ }^{14}$ Jayachandar et al. ${ }^{15}$ in which they concluded that 84 was most commonly affected by early loss but results contrasted to study conducted by Murshid et al., ${ }^{4}$ Leite-Cavalcanti et al. ${ }^{18}$ in which 85 was most commonly missing teeth. In the present study, more prevalence of caries was seen in primary second molars ( 85 followed by 75 ) but the early loss was seen in primary first molars compared with primary second molars. This was similar to the findings of Alamoudi. ${ }^{1}$ The reason for this might be due to the difference in the chronological age between the first and second primary molars, where the first primary molar erupted before the second primary molar and therefore it had been present in the oral environment for a longer period than the second primary molar. It also might be from a clinical point of view; while many clinicians would endeavor to restore a grossly carious second primary molar to maintain space, especially before the eruption of the first permanent molars, the first primary molars were usually extracted in such cases as the success rate of endodontics, which was the alternative treatment, was considerably lower. ${ }^{1}$

In the present study, more number of teeth were lost in the mandibular arch (48\%) when compared with the maxillary arch (35.7\%). These findings were similar to that of the findings of Alessandro Leite-Cavalcanti et al. ${ }^{18}$ and Kelner et al. ${ }^{19}$ The greater loss of primary molars in the mandibular arch might be due to food packing potential and greater plaque accumulation in the mandibular posterior region in contrast to the relative abundance of saliva and its anti-carious effect to maxillary molar teeth. ${ }^{9}$ Precocious loss of primary teeth was higher in the right side of the dental arch when compared with the left side of the arch. This could be because greater attention is paid to the left sides of both jaws during oral prophylactic procedures and masticatory processes as most people are right-handed. In our study, it was found that premature loss of primary teeth was more in the age group of 7-8 years, however, contrast results were seen in a study conducted by Murshid et al., ${ }^{4}$ Ahamed et al., ${ }^{13}$ and LeiteCavalcanti et al. ${ }^{18}$

Fluoroapatite which is formed through the ionic exchange between the enamel surface and the fluoride is more resistant to dissolution in acids than hydroxyapatite crystals of enamel. This anti-cariogenic action of fluoride might be the reason for a lower percentage of early loss of primary molars in this endemic fluoride area. Although these children had a low prevalence of early loss of primary teeth, this early loss may be attributed to parent's lack of knowledge regarding the chronology of exfoliation of primary teeth and their successor permanent teeth eruption, which leads to loss of arch length and crowding. After completion of screening in each school, the parents were counseled regarding the chronology of permanent teeth and the consequences of early loss of primary teeth.

\section{Conclusion}

The prevalence of early loss of primary teeth was comparatively less in fluoride area due to its anti-carcinogenic property. Lack of awareness regarding the importance of primary teeth is a contributing factor for this early loss of primary teeth in this area, hence educational and preventive programs should be implemented which would further reduce premature loss of primary teeth.

\section{References}

1. Alamoudi N. The prevalence of crowding, attrition, midline discrepancies and premature tooth loss in the primary dentition of children in Jeddah, Saudi Arabia. J Clin Pediatr Dent 1999;24(1): 53-58.

2. Cardoso L, Zembruski C, Femandes DS, et al. Evaluation of prevalence of malocclusion in relation to premature loss of primary teeth. Pesq bras odontoped clin integr 2005;5:17-22.

3. Brussola JAC. Ortodontia clinica. Barcelona, Moia: Sabat Editores; 1989. p. 508.

4. Murshid SA, Al-Labani MA, Aldhorae KA, et al. Prevalence of prematurely lost primary teeth in 5-10-year-old children in Thamar city, Yemen: a cross-sectional study. J Int Soc Prevent Communit Dent 2016;6(8):126-130. DOI: 10.4103/2231-0762.189739.

5. Ngan P, Alkire RG, Fields H. Management of space problems in the primary and mixed dentitions. J Am Dent Assoc 1999;130(9):13301339. DOI: 10.14219/jada.archive.1999.0403.

6. Popovich F, Thompson GW. Space maintenance. In: Preventive dental services Lewis DW, ed. 2nd ed., Ottawa, Canada: Minister of Supply Services; ; 1988. pp. 192-199.

7. Posen AL. The effect of premature loss of deciduous molars on premolar eruption. Angle Orlhod 1965;35:249-252. DOI: 10.1043/0003-3219(1965)0352.0.CO;2.

8. Al-Akwa AA, Ali Al-Maweri S. Dental caries prevalence and its association with fluoride level in drinking water in Sana'a, Yemen. Eur J Dent 2018;12(1):15-20. DOI: 10.4103/ejd.ejd_187_17.

9. Alamoudi N, Salako N, Masoud I. Prevalence and distribution of caries in the primary dentition in a cosmopolitan Saudi population. Saudi Dent J 1995;7:23-28.

10. Saravanan S, Kalyani V, Vijayarani MP, et al. Caries prevalence and treatment needs of rural school children in Chidambaram Taluk, Tamil Nadu, South India. Indian J Dent Res 2008;19(3):186-190. DOI: 10.4103/0970-9290.42948.

11. Kronfeld R. Development and calcification of the human deciduous and permanent dentition. The Bur 1935;35:18.

12. Padma Kuman B, Retnakumari N. Loss of space and changes in the dental arch after premature loss of the lower primary molar: a longitudinal study. J Indian Soc Pedod Prev Dent 2006;24(2):90-96. DOI: 10.4103/0970-4388.26023.

13. Ahamed SS, Reddy VN, Krishnakumar R, et al. Prevalence of early loss of primary teeth in 5-10-year-old school children in Chidambaram 
town. Contemp Clin Dent 2012;3(1):27-30. DOI: 10.4103/0976$237 X .94542$.

14. Reddy NV, Daneswari V, Shruti G, et al. Premature loss of primary teeth on arch dimensions in 6- to 10-year-old schoolchildren in Khammam town, Telangana state. Int J Pedod Rehabil 2018;3(2):67-71. DOI: 10.4103/ijpr.ijpr_28_17.

15. Jayachandar D, Gurunathan D, Jeevanandan G. Prevalence of early loss of primary molars among children aged 5-10 years in Chennai: a cross-sectional study. J Indian Soc Pedod Prev Dent 2019;37(2): 115-119. DOI: 10.4103/JISPPD.JISPPD_22_19.

16. Mahejabeen R, Sudha P, Kulkarni SS, et al. Dental caries prevalence among preschool children of Hubli: Dharwad city. J Indian Soc
Pedod Prev Dent 2006;24(1):19-22. DOI: 10.4103/0970-4388. 22829.

17. Lopez-Gomez SA, Villalobos-Rodelo JJ, Avila-Burgos L, et al Relationship between premature loss of primary teeth with oral hygiene, consumption of soft drinks, dental care, and previous caries experience. Sci Rep 2016;6(1):21147. DOI: 10.1038/srep21147.

18. Leite-Cavalcanti A, de Alencar CR, Bezerra PK, et al. Prevalence of early loss of primary molars in school children in Campina Grande. Brazil. Pak Oral Dent J 2008;28:113-116.

19. Kelner N, Rodrigues MJ, Miranda K. Prevalence of early loss of deciduous molars in children attending the FOP/UPE in 2002 and 2003. Dent Clin Sci Recife 2005;4:213-218. 